\title{
Population-level alcohol consumption and suicide mortality rate in South Korea: An application of multivariable spatial regression model
}

\author{
Yunho Yeom \\ Police Science Institute, Korean National Police University, Asan-si, Republic of Korea
}

\begin{abstract}
This research estimates the contextual effects of populationlevel alcohol consumption on the average suicide mortality rate (SMR) in South Korea from 2013 to 2015. The effect was estimated not only in relation to the risk factors of suicide, such as divorce and being elderly, but also protective factors, such as church attendance and educational attainment. Using a multivariable spatial regression model, results show that only excessive population-level alcohol consumption pattern had a positive effect on SMR by increasing 0.24 standardized units in the SMR; the moderate pattern, however, had no significant impact. These results imply that the excessive population-level alcohol consumption pattern is a risk factor with respect to SMR. This research suggests the implementation of policies to control population-level alcohol consumption, based on a concern for public health, to reduce the suicide risk in South Korea.
\end{abstract}

\section{Introduction}

According to the World Bank, the suicide mortality rate (SMR) of South Korea (Korea) in 2016 was 26.90 per 100,000 population, the fourth-highest worldwide (World Bank, 2016). In the past few decades, researchers have attempted to identify

\footnotetext{
Correspondence: Yunho Yeom, Police Science Institute, Korean National Police University, 100-50, Hwangsan-gil, Sinchang-myeon, Asan-si, Chungcheongnam-do, 31539, Republic of Korea.

Tel.: +82.041.968.2296 - Fax: +82.041.968.2982.

E-mail: yyeom@gradcenter.cuny.edu
}

Key words: Alcohol consumption; Suicide mortality rate; South Korea; Spatial analysis.

Conflict of interest: the author declares no potential conflict of interest.

Funding: none.

Received for publication: 20 October 2018.

Revision received: 5 March 2019.

Accepted for publication: 14 March 2019.

(C) Copyright Y. Yeom, 2019

Licensee PAGEPress, Italy

Geospatial Health 2019; 14:746

doi:10.4081/gh.2019.746

This article is distributed under the terms of the Creative Commons Attribution Noncommercial License (CC BY-NC 4.0) which permits any noncommercial use, distribution, and reproduction in any medium, provided the original author(s) and source are credited. underlying causes for Korea's high SMR by applying different theoretical and methodological frameworks (Lee et al., 2010; Lee and Kwon, 2015; Yoon et al., 2015). Most research has considered individual-level characteristics, such as depression and other psychological disorders, lack of adaptive skill and substance abuse, as major determinants for suicidal behaviour; few have examined contextual effects (Cheong et al., 2012). However, assuming that spatial variations in the SMR reflect contextual features of a location, exploring those variations has recently become a significant research concern (Yoon et al., 2015). The contextual approach is based on the idea by Durkheim (1897) that suicide cannot be solely understood at the individual level because suicide, as a social fact, is a product of the cross-level interaction between the individual and society.

Based on the contextual perspective, this research explores the spatial variations of the SMR in Korea and how contextual covariates of suicide contribute to such variations. Among several contextual predictors, this research focuses on population-level alcohol consumption. As researchers have consistently noted, even though alcohol consumption does not in itself cause suicide, it does significantly affect the SMR in a complicated interaction of individual, situational and other social factors (Sher, 2005). For this reason, researchers have examined the contextual effects of alcohol consumption on the SMR in the United States (U.S.) (Ramstedt, 2001; Kerr et al., 2011), Canada (Ramstedt, 2005), Russia (Pridemore et al., 2013), and Europe (Ramstedt, 2001), but rarely in Korea. Although some researchers have examined the effects of alcohol consumption on suicidal behaviour in Korea, they have focused on individual-level consumption only as a control variable (Park, 2013). Therefore, this research accounts for spatial variations in the SMR by focusing on population-level alcohol consumption.

\section{Alcohol consumption and the suicide mortality rate}

The association between alcohol consumption and suicidal behaviour has been established for both chronic and acute individual drinking patterns (Ramstedt, 2005; Landberg, 2009; Kerr et al., 2011). Chronic effects have been assumed to operate through the reciprocal relationship between alcohol consumption and other individual pathologies, such as depression, whereas acute effects have been assumed to temporarily weaken the operation of constraints that prevent suicidal behaviour (Cornelius et al., 1995; Kerr et al., 2011). Despite these differing mechanisms, researchers have consistently found positive associations between individuallevel alcohol consumption and suicidal behaviour (Cornelius et al., 1995). At the contextual level, relying on the findings of individual-level studies, but not being trapped in ecological fallacies, researchers have focused on the changes in per capita consumption as a proxy for population-level alcohol consumption. They have assumed that the changes in per capita consumption indicate both the frequency of intoxication occasions and the prevalence of 
heavy drinking in a population (Landberg, 2009: p.453). These two population-level indicators are assumed to be parallel to the two mechanisms of acute intoxication and chronic abuse at the individual level. Consequently, researchers have found a positive association between per capita consumption and SMR (Landberg, 2009) by utilizing time-series statistical techniques (Ramstedt, 2005; Landberg, 2009; Kerr et al., 2011; Phillips, 2013; Pridemore et al., 2013). For instance, Kerr et al. (2011) examined 53 years of data between 1950 and 2002 from 48 U.S. states with time-series techniques while controlling for unemployment rates. They found that the increase of total alcohol consumption had a significantly positive effect of $2.3 \%$ per litre on the SMR. Moreover, some researchers have found that the positive association was contingent upon a society's drinking pattern. For instance, Ramstedt (2001) examined 14 European countries with times-series statistical methods and found that the per capita consumption was in general positively associated with the SMR. However, the strength and significance of the association were conditioned by the country's drinking culture. A similar culturally contingent effect of per capita consumption was found in Canada (Ramstedt, 2005).

Even though previous studies of the contextual effects of alcohol consumption on the SMR found a positive association across time and place, they did not consider other covariates that might have mediated or confounded this association (Ramstedt, 2001). Several previous studies have found a set of contextual variables that has a positive or negative effect on the SMR. Researchers have usually found that divorce (Stack, 1982; Cheong et al., 2012; Yoon et al., 2015), education (Durkheim, 1897; Stack, 1982; Shah and Bhandarkar, 2009), unemployment (Kerr et al., 2011; Defina and Hannon, 2015), the Gini coefficients (Kowalski et al., 1987; Wadsworth and Kubrin, 2007), age (Stack, 1982; Lester, 1987), gender (Phillips and Nugent, 2014) and ethnic heterogeneity (Moore et al., 2014; Recker and Moore, 2016) are risk factors in the suicide rate. At the same time, researchers have consistently found that religious adherence (Stack, 1982, 1983; Bainbridge, 1989), mean income (Hooghe and Vanhoutte, 2011), effective clinical interventions (Blow et al., 2004), and the health infrastructure (James and Porter, 2012) are protective factors. However, the effects of both risk factors and protective factors on suicide have not been always consistent in their direction and strength, depending on the units of analysis and methodologies (Pompili et al., 2013). For example, the high level of education, which was assumed have a positive influence on the SMR by weakening the common faith within a society, sometimes showed opposite or mixed effects on suicide rate (Stack, 1998; Shah and Bhandarkar, 2009). This research estimates the contextual risk of population-level alcohol consumption on the average SMR in South Korea from 2013 to 2015 . The effect is not only estimated in relation to the risk factors, such as divorce and being elderly, but also with regard to protective factors, such as church attendance and educational attainment.

\section{Materials and Methods}

\section{Data source and measurement}

This research examines several datasets publicly available at the Korean Statistical Information Service database (KOSIS, 2017). For the dependent variable, the SMR, this research obtains cause-of-death data from the annual statistics between 2013 and
2015. The dataset provides the SMR per 100,000 population in different geographic regions. Suicide is relatively rare in many countries that might be unduly influenced by random fluctuations; thus, this research uses the average SMR between 2013 and 2015 (Wadsworth et al., 2014). In addition, this research uses Korean administrative units, $\mathrm{Si}$ (cities)-Gun (counties)-Gu (districts), as the units of analysis. The Si-Gun-Gu divides Korea into 250 units. Thus, the average SMR between 2013 and 2015 for each 250 SiGun-Gu in Korea is examined in light of alcohol consumption, divorce, church attendance, and education attainment. For contextual variables, such as population-level alcohol consumption and other socioeconomic predictors, this study uses datasets available at the KOSIS. All datasets were collected in 2015. The statistics on alcohol consumption compiled by the Ministry of Health and Welfare provide the percentage of population with different frequencies and prevalence rates of heavy drinking. In the dataset, consumption is measured as low (at least once a month) and excessive (women who drink more than three or men who drink more than five cans of beer more than twice a week) drinking pattern. Even though these two indicators do not directly present the per capita alcohol consumption in previous studies, they demonstrate what the concepts of per capita consumption indicate: both the frequency of intoxication occasions and the prevalence of heavy drinking in a population (Landberg, 2009: p. 453). Thus, two levels of consumption in the dataset are used as proxies for the population-level alcohol consumption.

In addition, church attendance is indicated by the percentage of population who believe in any religious denominations, including Buddhism, Protestantism, and Catholicism. The divorce rate is the percentage of population who is divorced. Drawing on Stack (1998), this research measures education not only by the percentage of population with at least a college degree, but also by the percentage of people with at least a college degree who are unemployed. Ethnic heterogeneity is measured by the percentage of population whose nationality is not Korean. Moreover, as a proxy for the health infrastructure (human and physical resources intended to alleviate the mortality rate), this research includes the number of psychiatrists per 10,000 population in each geographic unit.

\section{Analytical strategy}

Researchers have consistently pointed out that traditional studies assuming non-independence of observations have failed to consider that the influence of structural conditions spills over into adjacent neighbourhoods (Baller et al., 2001). These spillover effects are often larger than those of structural covariates themselves, and the covariates are severely constrained by the spatial context of adjacent neighbourhoods (Morenoff et al., 2001; p. 552). Thus, this research considers the spillover effects of spatially proximate units by using a two-pronged spatial analysis to examine the structural covariates of the SMR in Korea (Baller et al., 2001). The first phase of this research explores the spatial distribution and clustering of the SMR with several thematic maps and Moran's $I$ and Anselin's local indicator of spatial association (LISA) (Moran, 1950; Anselin, 1995; Anselin et al., 2006). Moran's $I$ shows a possible global spatial dependence in the SMR across Korea; the LISA produces a categorical outcome indicating positive or negative clustering at a more localized level. In the second phase, with spatial dependence in the model, this research identifies whether that spatial dependence is caused by either error or lag. When the dependence is caused by error, or by omitted variables, the spatial weight is applied to the error 
term in the regression equation (spatial error model). The error model can be presented as:

$\mathrm{Y}=\mathrm{X} \beta+\varepsilon, \quad \varepsilon=\lambda \mathrm{W} \varepsilon+\mu$

Eq. 1

where $\mathrm{Y}$ is the dependent variable; $\mathrm{X}$ the independent variable; $\varepsilon$ the vector of error terms; $W$ the spatial weight; $\lambda$ the autoregression parameter; and $\mu$ the vector of uncorrelated, homoscedastic errors (Baller et al., 2001).

When the spatial dependence is associated with substance (lag), or with the dependent variable by itself, the spatial weight is applied to the dependent variable (spatial lag model). The spatial lag model can be presented as:

$\mathrm{Y}=\rho \mathrm{Wy}+\mathrm{X} \beta+\varepsilon$

Eq. 2

where $\rho$ is the autoregression parameter; $\mathrm{W}$ the spatial weight; and $\varepsilon$ the error term (Baller et al., 2001). The term $\rho$ Wy indicates that the variation of $\mathrm{Y}$ in a specific unit is affected by the spatially weighted values of $Y$ in adjacent units. The spatial lag model indicates that the outcome variable depends not only on the independent variable within a location, but also on that of other neighbouring locations (Baller et al., 2001). Thus, depending on the result of the spatial dependency diagnostics using Lagrange multiplier (LM) statistic (Anselin and Rey, 1991), this study chooses one of these two models and analyzes the datasets with four additive multivariable spatial regression models.

In addition, this research applies the first order of queen as the spatial weight across spatial analyses because it indicates strong dependence than other orders of queen. Here, the queen contiguity is a type of spatial weight, which estimates the proximity of observation based on a common border or common vertices of each geographic unit of analysis (Maravi et al., 2017). When producing thematic maps for the visualization of variables, this research uses the Jenks natural breaks classification method, which minimizes each class's average deviation from the class mean and maximizes each class's deviation from the means of other groups (Chen et al., 2013). Finally, this research uses the GeoDa1.12.1.59 for spatial regression analyses (Anselin et al., 2006) and QGIS 2.18.19 for data visualization.

\section{Results}

\section{Descriptive statistics}

This research first analyzed the characteristics of each variable (summarized in Table 1).

Next, this research uses thematic maps to explore the spatial distribution of the SMR and the alcohol consumption indicator with the Jenks natural breaks classification. As seen in Figure 1, the SMR in the geographic units is unevenly distributed, evidenced by the fact that the high SMR is concentrated in the north-eastern and mid-western areas of Korea. Similarly, the percentage of population with excessive drinking patterns is clustered in the similar areas with a high SMR, as seen in Figure 2.

\section{Spatial autocorrelation and clustering in the suicide mortality rate}

There is also a statistically significant amount of spatial autocorrelation in the SMR. SMRs in the units are far from random, as evidenced by the positive slopes of the Moran's I coefficient $(0.425)$. The positive slope indicates when the SMR increases within a unit, those of neighbouring units also increase. In addition to Moran's I coefficients for SMR, as seen in Table 1, the coefficients for independent variables are found statistically significant with relatively high values.

Based on the strong global spatial dependence, this research examines potential clustering at the local unit in reference to the LISA. As seen in Figure 3, the 18 spatial units with a High-High relationship and the 14 units with a Low-Low relationship indicate positive association between the SMR of a unit and those of its neighbours. These 32 units significantly contribute to the positive global spatial autocorrelation. At the same time, the four units with a Low-High and High-Low relationship significantly contribute to a negative autocorrelation outcome. These results additionally demonstrate that the SMR in Korea is not randomly distributed at the local level. These spatial dependences and clusters are proper indicators not only for descriptive purpose, but also for multivariable spatial regression analysis (Porter and Purser, 2010).

Table 1. Descriptive statistics on variables.

\begin{tabular}{|c|c|c|c|c|c|}
\hline Variables & Minimum & Maximum & Mean & Standard Deviation & Moran's I \\
\hline $\begin{array}{l}\text { Outcome variable } \\
\text { Suicide Mortality Rate (per 100,000 population) }\end{array}$ & 15.1 & 63.5 & 30.6 & 7.9 & $0.52 * * *$ \\
\hline $\begin{array}{l}\text { Explanatory variables } \\
\text { Moderate Drinking (\%) } \\
\text { Excessive Drinking (\%) }\end{array}$ & $\begin{array}{c}34.2 \\
9.8\end{array}$ & $\begin{array}{l}69.1 \\
30.5\end{array}$ & $\begin{array}{l}55.8 \\
19.1\end{array}$ & $\begin{array}{l}6.4 \\
3.4\end{array}$ & $\begin{array}{l}0.67^{* * *} \\
0.14^{* *}\end{array}$ \\
\hline $\begin{array}{l}\text { Risk factors } \\
\text { Divorce Rate (\%) } \\
\text { Population over } 65(\%) \\
\text { Ethnic heterogeneity (\%) } \\
\text { College Degree or more (\%) } \\
\text { Unemployed College Degree (or more) holders (\%) }\end{array}$ & $\begin{array}{l}2.8 \\
5.4 \\
0.3 \\
7.2 \\
16.6\end{array}$ & $\begin{array}{l}9.3 \\
36.6 \\
26.5 \\
49.8 \\
54.5\end{array}$ & $\begin{array}{l}4.8 \\
17.6 \\
2.6 \\
17.7 \\
33.3\end{array}$ & $\begin{array}{l}1.1 \\
7.8 \\
2.8 \\
7.8 \\
5.8\end{array}$ & $\begin{array}{c}0.38^{* * *} \\
0.63^{* * *} \\
0.36^{* * *} \\
0.65^{* * *} \\
0.12 *\end{array}$ \\
\hline $\begin{array}{l}\text { Protective factors } \\
\text { Church Attendance Rate (\%) } \\
\text { Number of Psychiatrists (per 10,000 population) }\end{array}$ & $\begin{array}{c}33.0 \\
0.0\end{array}$ & $\begin{array}{l}58.4 \\
46.4\end{array}$ & $\begin{array}{c}44.0 \\
6.3\end{array}$ & $\begin{array}{l}4.4 \\
6.5\end{array}$ & $\begin{array}{c}045^{* * *} \\
0.05\end{array}$ \\
\hline
\end{tabular}

${ }^{*} \mathrm{P}<.05 ; * * \mathrm{P}<.01 ; * * * \mathrm{P}<.001$. 


\section{Multivariable spatial regression models}

This research also identifies the appropriate spatial model to control for the presence or absence of spatial dependence by testing whether the dependence is caused by error or lag (Baller et al., 2001). Running the ordinary least squares model in the GeoDa package, this research chooses the error model because the LM coefficients in the four models in Table 2 indicate that the error model has more significant value than the lag model (Anselin and Rey, 1991; Anselin et al., 2006). Table 3 presents the LM test results for Model 4. With this model specification, this research estimates the contextual effects on the SMR, as seen in Table 2. For all models, the spatially correlated error indicator $(\lambda)$ has a positive effect with a high significance.

In Model 1, this research tests the isolated effect of the alcohol consumption indicator on the SMR. This research finds that a oneunit increase in the percentage of population with an excessive drinking pattern significantly and positively affects the SMR by 0.61 units, but a one-unit increase of moderate drinking pattern does not significantly influence the SMR. These significant or nonsignificant effects of two drinking patterns remain constant across all models.

In Models 2 and 3, this research includes the five risk factors of suicide as control variables. In Model 2, this research finds that both the divorce rate and the percentage of elderly population strongly and positively influence the SMR, evidenced by the high coefficient values, 1.55 and 0.63 , respectively. Their effects on the SMR remain constant across all models with some slight changes in their coefficients. This research finds that the effects of education produce mixed results, depending on employment status. The percentage of unemployed people with college degrees positively affects the SMR, but the percentage of people with college degree negatively affects the SMR. Finally, this research incorporates the

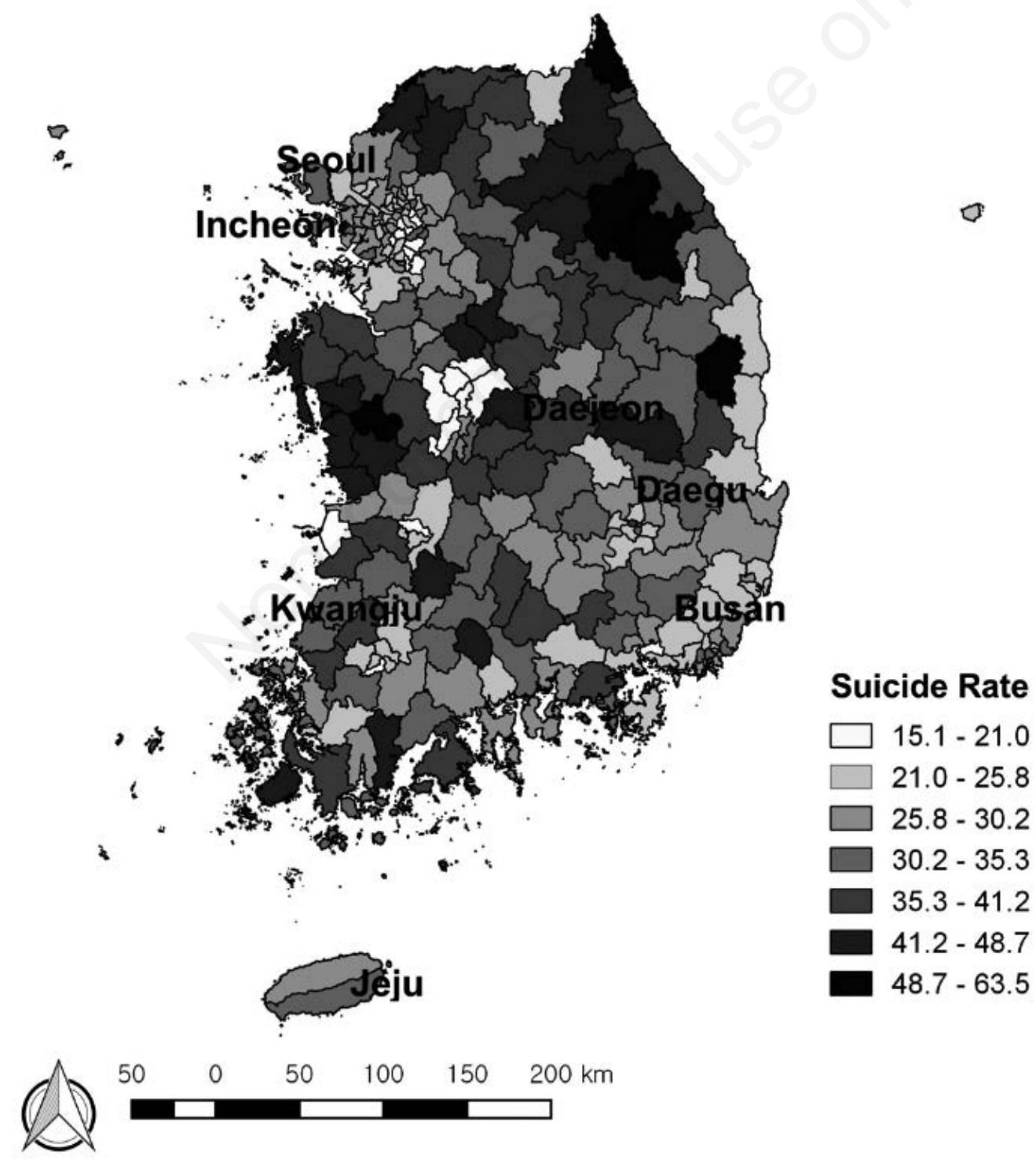

Figure 1. Spatial distribution of the suicide mortality rate (per 100,000 population) in Korea. 
Table 2. Spatial error models explaining the contextual covariates of suicide mortality rate.

\begin{tabular}{|c|c|c|c|c|c|}
\hline Structural Covariates & & Model 1 & Model 2 & Model 3 & Model 4 \\
\hline \multirow[t]{2}{*}{ Alcohol Consumption } & Moderate (\%) & 0.03 & 0.03 & 0.02 & 0.03 \\
\hline & Excessive (\%) & $0.61 * * *$ & $0.30 * *$ & $0.22 *$ & $0.24^{*}$ \\
\hline Risk Factors & $\begin{array}{l}\text { Divorce Rate (\%) } \\
\text { Age over } 65(\%) \\
\text { Ethnic Heterogeneity (\%) } \\
\text { College Degree (\%) } \\
\text { Unemployed College Degree Holders (\%) }\end{array}$ & $\begin{array}{l}- \\
- \\
- \\
-\end{array}$ & $\begin{array}{r}1.55^{* * *} \\
0.63^{* * *} \\
0.01 \\
- \\
-\end{array}$ & $\begin{array}{r}0.81^{*} \\
0.43^{* * *} \\
-0.02 \\
-0.37^{* * *} \\
0.12^{*}\end{array}$ & $\begin{array}{r}1.00^{* *} \\
0.57^{* * *} \\
0.01 \\
-0.22^{* *} \\
0.15^{* *}\end{array}$ \\
\hline \multirow[t]{2}{*}{ Protective Factors } & Church Attendance (\%) & - & - & - & $-0.25^{* *}$ \\
\hline & Psychiatrists (per 10,000) & - & - & - & -0.09 \\
\hline Constant & & $17.29 * * *$ & 4.39 & $16.00^{* * *}$ & $20.58^{* * *}$ \\
\hline Spatial Parameter $(\lambda)$ & & $0.48 * * *$ & $0.44^{* * *}$ & $0.44^{* * *}$ & $0.45^{* * *}$ \\
\hline R-Square & & 0.35 & 0.57 & 0.62 & 0.64 \\
\hline Akaike's information criterion & & 1659.73 & 1558.66 & 1531.67 & 1524.74 \\
\hline Moran's I for Residuals & & - & - & - & -0.002 \\
\hline
\end{tabular}

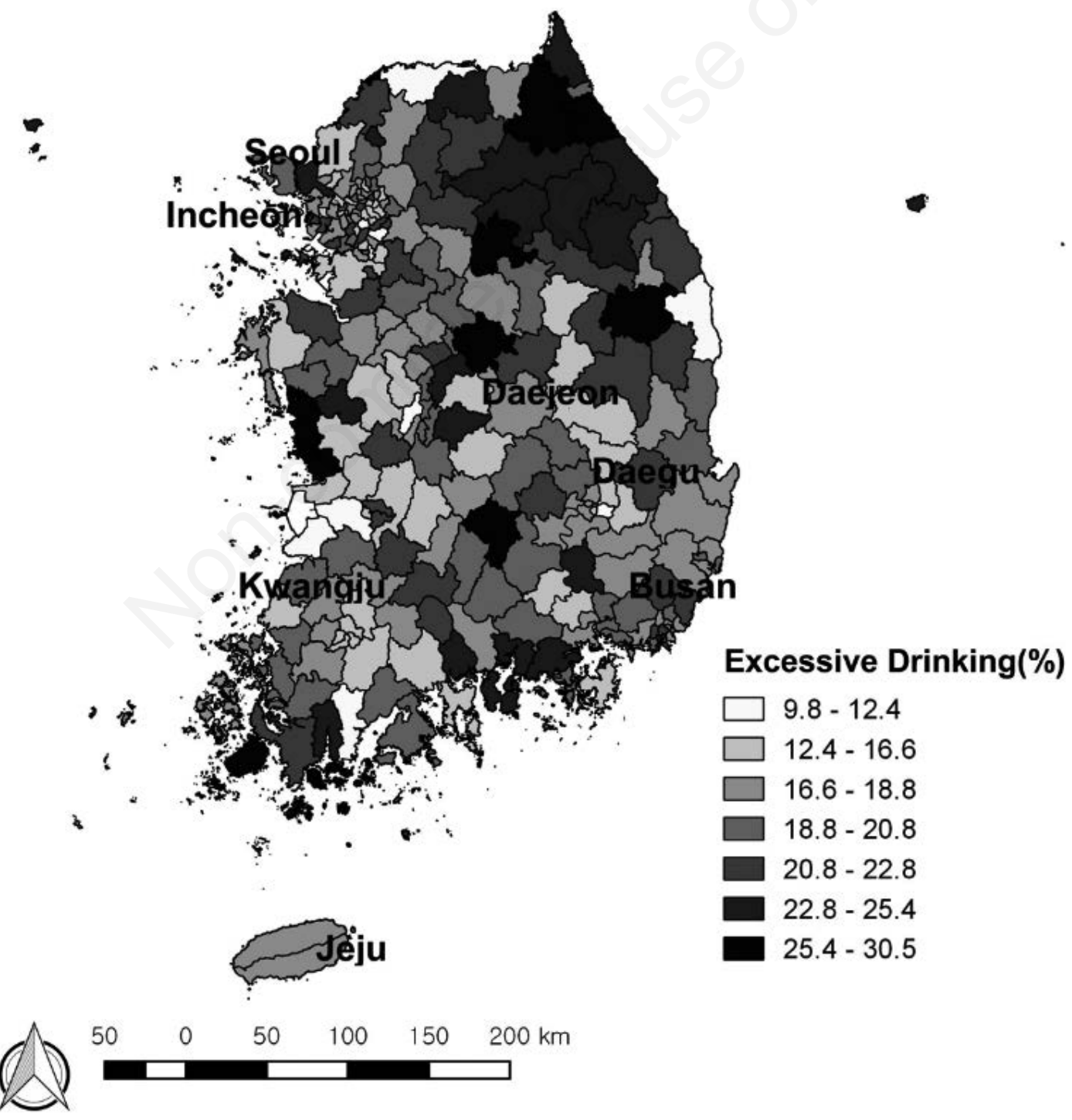

Figure 2. Spatial distribution of population with excessive alcohol consumption. 
two protective covariates of suicide as control variables in Model 4. Examination of these features reveals that on the one hand, church attendance rate negatively affects the SMR by decreasing 0.25 units of the SMR. On the other hand, the negative effect of number of psychiatrists on the SMR is marginally significant (Pvalue: 0.07$)$. The addition of all variables to Model 4 produces the best model fitness with the highest R-square and the lowest Akaike's information criterion values. Additionally, the non-significant value of Moran's $I$ for residuals in the Model 4 indicates that the spatial dependence in the model was controlled by the application of spatial error model.

\section{Discussion and Conclusions}

This research identified the contextual effects of populationlevel alcohol consumption on the SMR in Korea by controlling for risk factors and protective factors of suicide. This research indicat- ed that the distribution of SMR was spatially dependent in Korea, and that the population with excessive drinking patterns positively influenced SMR after controlling for other risk factors and protective factors of suicide. It was estimated that a one-unit increase in the population with excessive drinking pattern is associated with a 0.24- unit increase in the SMR. These findings are congruent with the results of previous studies which found a positive association between per capita alcohol consumption and the SMR in different locations (Landberg, 2009; Kerr et al., 2011).

Table 3. Results for Lagrange multipliers (LM) for Model 4.

\begin{tabular}{lccc} 
Test & MIIDF & Value & Probability \\
LM (lag) & 1 & 7.9028 & 0.0049 \\
Robust LM (lag) & 1 & 0.5070 & 0.4764 \\
\hline LM (error) & 1 & 40.6304 & 0.0000 \\
Robust LM (error) & 1 & 22.2346 & 0.0000 \\
\hline
\end{tabular}

MI, Moran's I; DF, degree of freedom.
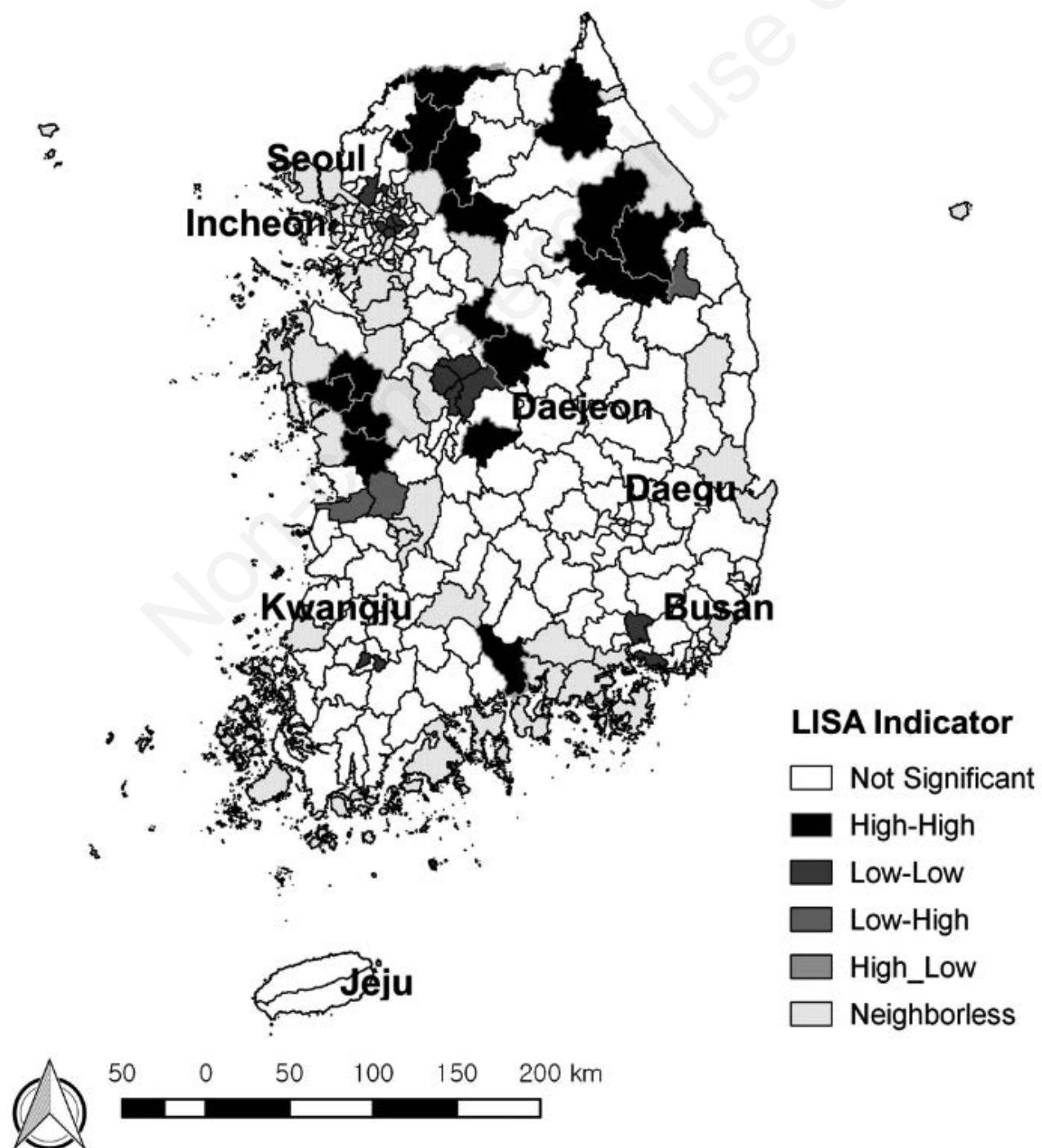

Figure 3. Anselin's local indicator for spatial association (LISA) for the suicide mortality rate. 
Therefore, as previous researchers have noted (Blow et al., 2004; Pridemore, 2013), an effective alcohol policy, including anti-alcohol campaigns or clinical interventions, need to be implemented in Korea to alleviate the deteriorating contextual effects of alcohol consumption on public health. As Seo et al. (2015) pointed out, Korea's approach to alcohol control policy has centred on regulating the alcohol beverage industry out of economic interest, not based on a concern for public health. This conclusion is indirectly supported by the finding of this study that the number of psychiatrists marginally, but negatively, affected Korea's SMR. However, these findings and interpretations need to be understood strictly at the contextual level, because the ecological fallacy does not allow researchers to draw inferences about individual behaviour from results based on aggregate data, or vice versa (Robinson, 1950).

One interesting finding in this research was that the effects of education on the SMR were contingent upon employment status. As Stack (1998) noted, the discrepancy between education and the expected status resulted in more psychological anomie in Korean populations. These findings can be supported by Korea's unique educational environment where academic success has been considered a key to success and is viewed as a survival response (Lee et al., 2010: p. 538). In this competitive educational environment, populations with high academic achievement are more likely to be frustrated when they are dissatisfied with their lives in general, as compared to the level that they had expected. In addition, unlike Durkheim (1897) who argued that the high education influences the SMR by weakening of the common faith within a society, a growing number of researchers has posited that education is associated with social or economic status (Stack, 1998; Pompili et al., 2013). This emerging view accounts for the differing effects of education in Korea where the high level of education in general leads to social success (Stack, 1998; Lee et al., 2010).

This research has the following strengths. It tested the effects of population-level alcohol consumption on suicide in Korea, a topic that has been rarely explored. In addition, this research identified several contextual covariates of the suicide rate beyond alcohol consumption; these findings supported that the contextual impact of alcohol consumption needs to be understood in terms of the interaction of individual, situational, and other social factors (Ramstedt, 2001; Sher, 2005). Furthermore, this research considered the spatial autocorrelation in examining those effects. Assuming that these findings are accurate, this research concludes that Korea belongs to the group of countries whose population-level alcohol consumption is positively associated with its SMR.

Nevertheless, there are some limitations in this research. This research considered the SMR for the entire population of Korea. As previous researchers have found, per capita alcohol consumption influenced the SMR of different demographic groups in different ways (Ramstedt, 2001; Pridemore et al., 2013). Thus, gender- or age-differing effects of alcohol consumption on the SMR in Korea need to be explored. Moreover, even though this research considered structural covariates beyond populationlevel alcohol consumption, it might have omitted variables that could affect the association, such as population-level depression (Lee and Kwon, 2015) and the use of antidepressants (McKeown et al., 2006). Thus, future studies needs to incorporate other possible structural covariates of the suicide rate.

\section{References}

Anselin L, 1995. Local indicators of spatial association - LISA. Geogr Anal 27:93-115.

Anselin L, Rey S, 1991. Properties of tests for spatial dependence in linear regression models. Geogr Anal 23:112-31.

Anselin L, Syabri I, Kyo Y, 2006. GeoDa: An introduction to spatial data analysis. Geogr Anal 38:5-22.

Bainbridge WS, 1989. The religious ecology of deviance. Am Sociol Rev 54:288-95.

Baller RD, Anselin L, Messner SF, Deane G, Hawkins DF, 2001. Structural covariates of U.S. county homicide rates: Incorporating spatial effects. Criminology 39:561-90.

Blow FC, Brockmann LM, Barry KL, 2004. Role of alcohol in late-life suicide. Alcohol Clin Exp Res 28:48-56.

Chen J, Yang S, Li H, Zhang B, Lv J, 2013. Research on geographical environment unit division based on the method of natural breaks (Jenks). Int Arch Photogramm XL:47-50.

Cheong KS, Choi MH, Cho BM, Yoon TH, Kim CH, Kim YM, Hwang IK, 2012. Suicide rate differences by sex, age, and urbanicity, and related regional factors in Korea. J Prev Med Public Health 45:70-7.

Cornelius JR, Salloum IM, Mezzich J, Cornelius MD, Fabrega H, Ehler JG, Ulrich RF, Thase ME, Mann JJ, 1995. Disproportionate suicidality in patients with comorbid major depression and alcoholism. Am J Psychiatry 152:358-64.

Defina R, Hannon L, 2015. The changing relationship between unemployment and suicide. Suicide Life Threat Behav 45:217-29.

Durkheim E, 1897. Suicide. Free Press, Glencoe, IL, USA.

Hooghe M, Vanhoutte B, 2011. An ecological study of community-level correlates of suicide mortality rates in the Flemish region of Belgium, 1996-2005. Suicide Life Threat Behav 41:453-64.

James WL, Porter JR, 2012. Inequality, health infrastructure, and spatial context: Understanding pathways to variations in the causal determinants of race-specific mortality rates. Sociol Spectr 32:322-45.

Kerr WC, Subbaraman M, Ye Y, 2011. Per capita alcohol consumption and suicide mortality in a panel of US states from 1950 to 2002. Drug Alcohol Rev 30:473-80.

Korean Statistical Information Service (KOSIS), 2017. Cause of death statistics between 2000 and 2016. Available from: http://kosis.kr/statHtml/statHtml.do?orgId=101\&tblId=DT 1 B34E13\&vw_cd=MT_ZTITLE\&list_id=D11\&seqNo=\&lang mode $=$ ko\&language $=$ kor\&obj_var_id $=\& i t m \_i d=\&$ conn_pat $\overline{\mathrm{h}}=\mathrm{MT}$ ZTITLE

Kowalski GS, Faupel CE, Starr PD, 1987. Urbanism and suicide: A study of American counties. Soc Forces 66:85-101.

Landberg J, 2009. Per capita alcohol consumption and suicide rates in the U.S., 1950-2002. Suicide Life-Threat Behav 39:452-9.

Lee DE, Kwon SW, 2015. Community-level factors and adolescent depression in South Korea: Socioeconomic composition, education environment, and community wellbeing. Child Indic Res 8:459-70.

Lester D, 1987. Murders and suicide: Are they polar opposites? Behav Sci Law 5:49-60.

Maravi ME, Snyder LE, McEwen LD, DeYoung K, Davidson A, 2017. Using spatial analysis to inform community immunization strategies. Biomed Inform Insights 9:1-13. 
McKeown R, Cuffe SP, Schultz RM, 2006. US suicide rates by age group, 1970-2002: An examination of recent trends. Am J Public Health 6:1744-51.

Moran PAP, 1950. Notes on continuous stochastic phenomena. Biometricka 37:17-23.

Moore MD, Recker NL, Heirigs M, 2014. Suicide and the creative class. Soc Indic Res 119:1613-26.

Morenoff JD, Sampson RT, Raudenbush SW, 2001. Neighborhood inequality, collective efficacy, and the spatial dynamics of urban violence. Criminology 39:517-60.

Park SH, 2013. Predictors of suicidal ideation in late childhood and adolescence: A 5-year follow-up of two nationally representative cohorts in the Republic of Korea. Suicide Life-Threat Behav 43:81-96.

Phillips JA, 2013. Factors associated with temporal and spatial patterns in suicide rates across U.S. states, 1976-2000. Demography 50:591-614.

Phillips JA, Nugent CN, 2014. Suicide and the great recession of 2007-2009: The role of economic factors in the 50 U.S. states. Soc Sci Med 116:22-31.

Pompili M, Vichi M, Qin P, Innamorati M, Leo DD, Girardi P, 2013. Does the level of education influence completed suicide? A nationwide register study. J Affect Disord 147:437-40.

Porter JR, Purser CW, 2010. Social disorganization, marriage, and reported crime: A spatial econometrics examination of family formation and criminal offending. J Crim Justice 38:942-50.

Pridemore WA, Chamlin MB, Andreev E, 2013. Reduction in male suicide mortality following the 2006 Russian alcohol policy: An interrupted time series analysis. Am J Public Health 103:2021-6.

Ramstedt M, 2001. Alcohol and suicide in 14 European countries. Addiction 96:59-75.

Ramstedt M, 2005. Alcohol and suicide at the population level-the Canadian experience. Drug Alcohol Rev 24:203-8.
Recker NL, Moore MD, 2016. Durkheim, social capital, and suicide rates across US counties. Health Sociol Rev 25:78-91.

Robinson W, 1950. Ecological correlations and the behavior of individuals. Am Sociol Rev 15:351-7.

Seo S, Chun S, Newell M, Yun M, 2015. Korean public opinion on alcohol control policy: A cross-sectional international alcohol control study. Heath Policy 119:33-43.

Shah A, Bhandarkar R, 2009. The relationship between general population suicide rates and education attainment: A crossnational study. Suicide Life-Threat Behav 39:463-70.

Sher L, 2005. Alcohol use and suicide rates. Med Hypothesis 65:1010-2.

Stack S, 1982. Suicide: A decade review of the sociological literature. Deviant Behav 4:41-66.

Stack S, 1983. The effect of the decline in institutionalized religion on suicide. J Sci Stud Relig 22:239-52.

Stack S, 1998. Education and risk of suicide: An analysis of African Americans. Sociol Focus 31:295-302.

Wadsworth T, Kubrin CE, 2007. Hispanic suicide in U.S. metropolitan areas: Examining the effects of immigration, assimilation, affluence, and disadvantage. Am J Sociol 112:1848-85.

Wadsworth T, Kubrin CE, Herting JR, 2014. Investigating the rise (and fall) of young black male suicide in the United States, 1982-2001. J Afr Am Stud 18:72-91.

World Bank, 2016. Suicide mortality rate (per 100,000 population). Available from: https://data.worldbank.org/ indicator/ SH.STA.SUIC.P5. Accessed: February 26, 2019.

Yoon TH, Noh MS, Han JH, Jung-Choi KH, Khang YH, 2015. Deprivation and suicide mortality across 424 neighborhoods in Seoul, South Korea: a Bayesian spatial analysis. Int J Public Health 60:969-76. 